\title{
O Livro XVII das Institutiones grammaticae de Prisciano: permanência ou descontinuidade em Tomás de Erfurt e Jeronymo Soares Barbosa
}

\author{
Alessandro Jocelito Beccari \\ Universidade Estadual Paulista "Júlio de Mesquita Filho" (UNESP), \\ Assis, São Paulo, Brasil \\ jbeccari1@yahoo.com.br \\ http://orcid.org/0000-0001-6230-741X
}

DOI: http://dx.doi.org/10.21165/el.v47i1.1965

\begin{abstract}
Resumo
Este artigo apresenta e discute resultados de uma pesquisa atualmente em desenvolvimento, que se fundamenta na tradução do original latino do livro XVII das Institutiones Grammaticae de Prisciano Cesariense (ca. 500 d.C.). O principal objetivo deste artigo é cotejar as ideias de Prisciano (séc. VI), do gramático especulativo Tomás de Erfurt (séc. XIII) e de Jeroymo Soares Barbosa (séc. XVIII), do ponto de vista de suas respectivas teorias do caso nominal do latim, para verificar continuidades ou desconcontinuidades nos dois últimos em relação ao primeiro. O modelo aqui adotado é a Historiografia Linguística (HoL): Koerner (1989) e Swiggers (2004). Palavras-chave: Historiografia Linguística; Prisciano; Tomás de Erfurt; Jeronymo Soares Barbosa.
\end{abstract}

\section{Priscian's book XVII of the Institutiones grammaticae: permanence or discontinuity in Thomas of Erfurt and Jeronymo Soares Barbosa}

\begin{abstract}
This article presents and discusses some results of a current research that is based on the translation of the Latin original of book XVII of the Institutiones Grammaticae of Priscianus Caesariensis (ca. 500 A.D.). The main objective of this article is to compare the ideas of Prisciano (6th century), of the speculative grammarian Thomas of Erfurt (13th century) and Jeronymo Soares Barbosa (18th century) from the point of view of their respective Latin case theories in order to verify the continuities or discontinuities of the latter two in relation to the former. The theoretical model used in this article is Historiography of Linguistics (HoL): Koerner (1989) and Swiggers (2004).
\end{abstract}

Keywords: Historiography of Linguistics; Priscian; Thomas of Erfurt; Jeronymo Soares Barbosa.

\section{Considerações iniciais}

Este artigo apresenta e discute alguns resultados de uma pesquisa de natureza histórica, filosófica e linguística, ainda em andamento, que tem como base a tradução do original latino do livro XVII das Institutiones Grammaticae de Prisciano Cesariense (ca. 500 d.c.). O projeto visa a entender a possível permanência ou descontinuidade das teorias sintáticas que se desenvolveram historicamente a partir dos livros sobre sintaxe da gramática de Prisciano e tiveram grande influência nas teorias do modista Tomás de Erfurt em sua Gramática especulativa (séc. XIII). Além disso, quer-se verificar os pontos de continuidade e descontinuidade das teorias de Prisciano e de Tomás de Erfurt na 
tradição gramatical luso-brasileira nas últimas décadas do séc. XVIII e início do séc. XIX, especificamente, no trabalho intitulado As duas línguas, ou grammatica philosophica da lingua portugueza comparada com a latina, para ambas se aprenderem ao mesmo tempo, publicada em 1807, de autoria de Jeronymo Soares Barbosa (1737-1816). Em seu trabalho, o gramático, educador e classicista português discute as sintaxes latina e portuguesa do ponto de vista da Gramática Geral.

É possível que as ideias de Prisciano sobre sintaxe estejam na origem dos desenvolvimentos que culminariam, no séc. XVII, na Grammaire générale et raisonnée dos mestres de Port-Royal e, no séc. XVIII, n'As duas línguas de Jeronymo Soares Barbosa. Nesse sentido, assume-se que, ao longo da história, houve uma corrente filosófica da Gramática Tradicional (GT), a qual se constituiu em gramáticas ou textos gramaticais que tiveram o latim como língua de análise, a começar pelas reflexões do romano Varrão (séc. I a.C.), passando pelas Institutiones de Prisciano, pelos gramáticos especulativos medievais (séc. XIII), por Sanctius (séc. XVI) e Port-Royal, alcançando o contexto luso-brasileiro n'As duas línguas de Jeronymo Soares Barbosa (1807). Devido à grande extensão de tempo e assunto, a principal tarefa deste artigo limitar-se-á a verificar a hipótese da vertente filosófica a partir do cotejo das ideias de Prisciano (séc. VI), do especulativo Tomás de Erfurt (séc. XIII) e de Soares Barbosa, do ponto de vista de uma questão específica: aspectos particulares das teorias do caso nominal do latim presentes nos trabalhos desses três gramáticos.

\section{Declinação: natural e livre}

No Ocidente latino, a história das reflexões linguísticas a respeito do caso nominal começa com o trabalho de Marco Terêncio Varrão (116-27 a.C.) em seu De lingua latina. Dessa coleção de 25 livros só nos chegaram cinco: os de número V a X. Destes, VIII, IX e X são fundamentais para o assunto abordado neste artigo, já que é nessas três obras que Varrão, pela primeira vez no mundo romano, estabelece definições precisas dos conceitos de flexão, declinação e derivação das palavras, em que introduz a noção de paradigmas verbais e nominais na gramática latina. A motivação que dá origem ao trabalho teórico do estudioso romano é a famosa controvérsia entre analogistas e anomalistas, que foi, sem dúvida, uma das questões linguísticas mais desafiadoras da Antiguidade. Em seu De lingua latina, Varrão elabora tratados em que se propõe a considerar essa questão. $\mathrm{O}$ resultado são os fundamentos de uma teoria do caso nominal que encontrará lugar canônico na tradição da gramática latina. O clima de opinião dessa controvérsia é influenciado pela visão estoica acerca do universo e da linguagem.

Os estoicos defendiam a anomalia como princípio natural da linguagem: a ideia segundo a qual existem mais exceções e irregularidades do que proporcionalidades ou analogias na linguagem. Para eles, as regularidades das línguas seriam construções consensuais (sociais) que não teriam relação com um princípio central de diferenciação natural das línguas entre si. Na verdade, essa diferenciação baseava-se no materialismo estoico, para o qual:

O mundo é composto de indivíduos e [...] não há dois ovos, dois grãos de trigo, dois irmãos que sejam rigorosamente semelhantes; cada um possui 'qualidade própria', um hidios poión que o caracteriza, o distingue e o constitui [...] para os Estóicos, a individualidade é uma noção fundamental e constitutiva (BRUN, 1986, p. 50). 
Em oposição ao materialismo estoico que só contemplava diferenças, havia também, ao tempo de Varrão, as opções aristotélica e platônica, em que, grosso modo, o indivíduo é uma instância de uma ideia geral ou essência. Nesse sentido, muitos aspectos das línguas são claramente manifestações de princípios racionais que não equivalem a construções humanas, mas a regras analógicas subjacentes e universais. É nesse sentido que Varrão identifica o princípio de analogia na declinação dos nomes:

O sistema de declinações foi introduzido não apenas na língua latina, mas em todas as línguas do homem, porque é útil e necessário; se este sistema não tivesse sido desenvolvido, nós não poderíamos aprender um número tão grande de palavras quanto aprendemos (pois são infinitas na natureza as formas em que são declinadas), e não teríamos aprendido as que vêm destas, e quais provêm da relação que têm entre si. Mas, como é assim, nós vemos, por essa razão, quais são parecidas e quais delas se propagam [...] (VARRÃO, VIII, 3).

Varrão se impôs o trabalho de abordar a controvérsia "analogia x anomalia" e, segundo Robins (1987, p. 37), "grande parte de sua descrição e análise do latim decorre do tratamento que deu a esse problema".

Como se sabe, tanto em grego quanto em latim, bem como em outras línguas em que as palavras possuem flexões de caso, pessoa, número etc., a maioria das classes paradigmáticas nominais e verbais admitem exceções - membros irregulares -, basta pensar nos verbos defectivos e anômalos do português. Este já seria um ponto importante a favor do princípio da anomalia, entretanto, além disso, "[...] ao contrário do que dita o princípio da analogia, há palavras que fogem à regra e não seguem um paradigma flexional, e estas formas anômalas devem ser, portanto, memorizadas" (VALENZA, 2010, p. 13). Portanto, a abundância de irregularidades nas línguas poderia, de fato, levar à conclusão de que as línguas, no fundo, não obedecem a quaisquer princípios racionais e seu funcionamento só é previsível graças a normas impostas externamente. Qual foi a proposta de Varrão ante essas evidências? Surpreendentemente, sua solução vem de um campo hoje muito pouco frequentado pelos linguistas: a etimologia.

Embora a teoria da origem das palavras de Varrão possa ser considerada hoje em dia um tanto mitológica, é a partir dela que ele descobriu uma solução para a controvérsia em pauta. O gramático romano propôs que todos os vocabulários de todas as línguas desenvolveram-se a partir de um reduzidíssimo número de palavras originárias, isto é, de um vocabulário original. Essas palavras originárias, por um processo de mudança, deram origem a todas as palavras em uso pelo ser humano atualmente. Segundo Robins (1987, p. 38), ao propor essa teoria:

Varrão reuniu dois planos distintos de estudo: a etimologia histórica e a formação sincrônica por meio da derivação e flexão. Dentro de cada paradigma, certas palavras foram consideradas como básicas e as outras como produto da 'declinação' (declinatio), processo de mudança formal. Aos prefixos derivacionais se concedeu especial atenção no capítulo 38 do livro 6.

Varrão dividiu a noção de "declinação" (declinatio) em declinatio naturalis (declinação natural) e declinatio uoluntaria (declinação livre). Ademais, dividiu a derivação natural em dois tipos: flexivo-desinencial e derivativo-afixal, ou seja, as flexões 
verbais e as declinações nominais (das línguas de caso) e a derivação das palavras por afixação (sufixos e prefixos) ${ }^{1}$.

Com essas categorizações, Varrão dava uma resposta linguística à controvérsia em questão: se na declinatio naturalis impera o princípio da analogia, na declinatio uoluntaria predomina o da anomalia, responsável pelo crescimento do vocabulário das línguas. Ou seja, as línguas são essencialmente sistemas analógicos abertos.

O resultado mais importante das reflexões de Varrão sobre esse assunto, para nossa discussão neste artigo, é duplo, pois deu origem a uma distinção e uma noção muito importantes para a história da gramática latina que se deriva delas: a distinção entre declinação nominal e flexão verbal e a noção de paradigma, a saber: "O conjunto completo das formas flexionadas de uma mesma palavra, especialmente quando é tomado como exemplo" (TRASK, 2011, p. 221).

A descoberta desse conjunto ou modelo de formas flexionadas não resultou apenas em um instrumento que se mostrou de grande auxílio, ao longo dos séculos, na aprendizagem de idiomas (como o grego, o latim, o árabe, o hebraico, os vernáculos europeus e as línguas não indo-europeias), mas também viabilizou a utilização das formas de um paradigma específico, o do pronome relativo e interrogativo latino (qui/s, quae, quod/id) como expoentes de todas as relações sintáticas ligadas ao sistema de casos da língua latina, ou seja, como formalização do núcleo da sintaxe do latim. Veremos a seguir como essa evolução começa a acontecer no De constructione (outro nome do Livro XVII das Institutiones) de Prisciano Cesariense (séc. VI d.C.) e se concretiza na Gramática especulativa, de Tomás de Erfurt (séc. XIII).

\section{Do paradigma de quod à semiformalização das relações sintáticas}

Prisciano é um analogista convicto. Compara pares de coisas parecidas entre si, mas de níveis diferentes. Assim, observa a relação de semelhança entre a disposição linear de letras e sílabas, entre sílabas e palavras, entre palavras e frases, e encontra coincidências entre esses níveis: letras, sílabas, palavras, frases. De fato, em sua sintaxe, objetiva encontrar relações proporcionais, simétricas, entre os diferentes elementos e níveis da linguagem. Sua linha de pensamento é baseada em proporções de tipo: 1 está para 2 assim como 10 está para 20. Por exemplo, disco ("aprendo", presente do indicativo) está para discam ("aprenderei", futuro do indicativo) assim como didici ("aprendi", perfeito do indicativo) está para didicero ("terei aprendido", futuro do perfeito). Esse gramático de Constantinopla, atuante no início do séc. VI, defende a existência de formas diferentes como comprovação empírica de sua tese analógica: as diferenças entre as formas refletiriam as relações proporcionais que Prisciano tentava demonstrar. É preciso que haja formas diferentes para explicar e dar conta das realidades diferentes da linguagem. Nesse sentido, a gramática de Prisciano é de caráter morfossintático e nocional (BORGES NETO; DASCAL, 2004): baseia-se em análises morfossintáticas para tirar conclusões a respeito do significado.

\footnotetext{
${ }^{1}$ A declinatio naturalis é responsável pela criatividade linguística e responderia a uma pergunta feita há não muito tempo pela mídia brasileira: "presidenta" é forma abonada?
} 
Segundo Prisciano, a linguagem reflete a realidade. Se existe alguma coisa ou relação no mundo, tem correspondência na língua. Por exemplo, se não houvesse a distinção $e u$, tu e ele como eu e tu e outra coisa, na linguagem também não existiria tal distinção. Isso reflete o conteúdo filosófico do pensamento gramatical de Prisciano, que agrega elementos de influência aristotélica, estoica e platônica. A ideia de que haja correspondência entre entidades linguísticas e coisas no mundo permite que as teorias de Prisciano sejam classificadas como pertencentes ao que Swiggers (2004) chama de um programa de correspondências.

A metafísica aristotélica tem grande influência nas assunções epistemológicas de Prisciano. A questão da substância (ousia) e dos acidentes (kategoriai) da substância, muito viva no contexto bizantino em que Prisciano atuou (séc. VI) devido a controvérsias sobre a natureza de Cristo (divina e humana) e da Trindade (três pessoas, uma substância), está presente em suas discussões gramaticais, funcionando, de fato, como princípio para procedimentos de análise gramatical, como mostra a passagem a seguir.

O qui relativo responde a este pronome, isto é, quis, que é interrogativo: quis scripsit Bucolica? qui etiam Georgica. Este quis interrogativo, entretanto, também se liga a um nome próprio quando os verbos substantivos ou vocativos possuem valor semelhante. Ele é respondido também por um pronome: quis est Trypho? ou quis nominatur Trypho? ego ou tu ou ille. Ou, do contrário, quando um pronome se junta a quis, responde-se com um nome: quis est ille? ou quis vocatur? Achilles. Também é evidente, a partir disso, que, quando junta-se a um nome suposto, buscamos a substância definida do suposto em alguma pessoa certa, que, de fato, somente os pronomes revelam - a demonstração dos quais cossignifica os acidentes; daí que [os pronomes] dizem respeito a todo o suposto.

Porém, quando quis se associa aos pronomes, [já] conhecemos, de fato, a substância, mas [ainda] não a propriedade da qualidade que é explicada pelo nome. E fica claro que os pronomes são tomados no lugar dos nomes próprios, quando são entendidos a partir da sua própria interrogação. Quando, com efeito, eu pergunto: quis es tu?, ou ille?, sem dúvida eu estou falando das substâncias definidas de certas pessoas, das quais quero saber também as propriedades, e também quando se oferecem respostas pronominais a partir de nomes próprios: quis est Trypho? ego ou ille ${ }^{2}$.

Nesse excerto, vemos que a construção do pronome interrogativo com outras partes da frase pode revelar se a pergunta é a respeito da substância ou dos seus acidentes: quando a construção é de tipo "quis + verbo substantivo/vocativo + nome (próprio)" procura-se saber a respeito de uma substância e de seus acidentes. Quando, porém,

\footnotetext{
${ }^{2}$ Huic nomini, id est quis, quod est interrogatiuum uel infinitum, redditur qui relatiuum: quis scripsit Bucolica? qui etiam Georgica. Hoc tamen, id est quis interrogatiuum, proprio quoque adiungitur cum uerbis substantiuis uel uocatiuis similem uim habentibus. Et pronomen etiam redditur huic: quis est Trypho? uel quis nominatur Trypho? - ego uel tu uel ille, uel e contrario cum pronomine adiunctum quis nomen disiderat sibi reddi: quis est ille? uel quis uocatur? Achilles. Et manifestum ex hoc quoque quod, quando nomini adiungitur substantiam definitam in aliqua certa persona quaerimus suppositi; hanc enim solam ostendunt pronomina quorum demonstratio sibi quoque accidentia consignificat, unde ad omne suppositum pertinent. Quando uero pronominibus iungitur quis, substantiam quidem intellegimus, non etiam proprietatem qualitatis, quae nomine explanatur.

Et est manifestum quod loco proprium nominum pronomina accipiuntur, cum ex eorum interrogatione proprie intelleguntur. Cum enim dico quis es tu? uel ille? sine dubio de quibusdam finitis hoc dico substantiis, in quibus etiam proprietates desidero scire, et cum a propriis quoque pronominatiuae redditiones fiunt: quis est Trypho? ego uel ille (PRISCIANO, 2, 129, 5-130, 2).
} 
pergunta-se com o uso de uma construção do tipo "quis + verbo substantivo + pronome", quer-se saber a respeito apenas dos acidentes, pois a substância já é conhecida. Ressaltese, nessa passagem, que o correspondente gramatical da categoria metafísica da substância é o que Prisciano chama de "suposto", que traduz um conceito da lógica: o suposto ("posto debaixo de") refere-se a todos os itens denominados pelo nome ou pronome que se encontram no mundo. O termo técnico "suposto" terá um longo percurso na história da lógica e nomeará a entidade básica da teoria da suposição, cujo principal expoente será Guilherme de Ockham (ca. 1268-1350).

Segundo Kelly (2002), Aristóteles, em seu Da Interpretação (3 16b6), definira o nome como o outro do verbo. Os gramáticos modistas do final da Idade Média construiriam sua teoria do caso com base nessa definição aristotélica ${ }^{3}$. Para os modistas, o nome é o alterum (o outro) do verbo em uma construção básica de tipo "verbo + nome" (por exemplo, em "João corre", "João" é o outro de "corre").

Os modistas também passaram a usar o paradigma do pronome qui, no gênero neutro (quod), para explicitar as relações entre o verbo e o outro: o nominativo era entendido como significando ut quod est alterum ("enquanto quod ('que'[NOM./sujeito ou predicativo]) é o outro"), o genitivo ut cuius est alterum ("enquanto cuius ('de que' [GEN./sujeito ou adjunto adnominal restritivo]) é o outro"), o acusativo ut quem est alterum ("enquanto quem (que[AC./objeto direto ou sujeito de oração reduzida]) é o outro") e assim por diante.

As formas do paradigma qui, quae, quod como expoentes das relações dos elementos nominais da oração entre si, e destes com o verbo, estão presentes no $D e$ constructione, como demonstra a leitura do excerto a seguir.

Este mesmo qui ("que") muitas vezes é posposto ao nome como, para os gregos, hós. É proferido necessariamente não só com relação ao nome precedente, mas também ao verbo posposto, como em: virum cano qui venit ("canto o homem que vem"). Se ao nominativo adjunge-se outro nominativo, os verbos referem-se à mesma pessoa: homo venit qui scripsit ("o homem que vem, escreve"); porém, se são dois os termos em caso oblíquo, a transição dos verbos é feita para a outra pessoa ou de maneira recíproca, como hominem, quem vitupero, accuso ("acuso o homem a quem censuro") et memet quem uitupero, accuso ("acuso a mim mesmo, a quem censuro"); se, porém, um termo é nominativo e o outro é oblíquo, não se faz a transição do verbo para o nominativo de uma pessoa para a outra, mas é feita para o oblíquo, como: homo venit quem accuso ("vem o homem a quem acuso") ou: hominis misereor qui venit ("tenho piedade do homem que vem").

No entanto, todas as coisas que podem ser feitas transitivamente, podem ser feitas também de maneira recíproca. Assim, qui e todas as suas formas oblíquas referem-se também aos nominativos de todas as palavras com flexão de caso, como: Virgilius, qui scripsit ("Virgílio, que [NOM.] escreveu"); Virgilius, cuius scripta extant ("Virgílio, de quem [GEN.] sobrevivem os escritos"); Virgilius, cui gloria contigit ("Virgílio, para quem [DAT.] cabe a glória"); Virgilius, quem laudant ("Virgílio, que [AC.] louvam"); Virgilius, quo docente bene proficitur ("Virgílio, por cujo ensino [ABL.] progride-se bem").

\footnotetext{
${ }^{3}$ Além disso, os modistas agregaram, em sua explicação sistemática do caso nominal, outros elementos da física do movimento, da lógica e da metafísica aristotélica, superando as análises lineares de Prisciano.
} 
Também no sentido contrário todos os outros casos adjungem-se bem ao nominativo, como: qui scripsit bucolica Virgilius magnus poeta fuit ("quem escreveu as Bucólicas foi o grande poeta Virgílio [NOM.]"); qui scripsit Aeneida Virgilii sunt Georgica ("as Geórgicas são de Virgílio [GEN.] que escreveu a Eneida"); qui scripsit Aeneida Virgilio gloria contigit ("a Virgílio [DAT.], que escreveu a Eneida, cabe a glória"); qui scripsit Aeneida Virgilium laudo ("louvo a Virgílio [AC.], que escreveu a Eneida"); qui scripsisti Aeneida, Virgili, uiuis memória ("ó Virgílio [VOC.], que escreveste a Eneida, vives na memória"); qui scripsit Aeneida Virgilio florent studia ("por causa de Virgílio [ABL.], que escreveu a Eneida, os estudos florescem"). É possível também expressar essas coisas antepondo esses termos. ${ }^{4}$

Observemos, no excerto acima, que o uso do pronome, em Prisciano, dependendo de sua posição em relação às outras partes das frases, coordena os tipos de relação que podem ocorrer: de transitividade ou reciprocidade.

Diferentemente do senso comum atual (GT) a respeito da transitividade, para os modistas, como já o fora para Prisciano, não existem verbos transitivos ou intransitivos: há, na verdade, construções transitivas ou intransitivas. Isso porque, a relação de transitividade - tanto na gramática da Antiguidade Tardia (ca. 300-470 d.C.) quanto na da Baixa Idade Média (séc. XIII ao séc. XV) - tem a ver com a mudança de referente do discurso. Assim, "João corre" é uma construção intransitiva porque a ação representada pelo verbo não significa uma ação que transita para outro referente, mas que permanece em "João". Por outro lado, uma construção como "João ama Maria" é transitiva, porque a ação significada transita de um referente a outro/faz referência a mais de um referente. Ou seja, trata-se de uma questão de correferenciabilidade (transitividade) ou não (intransitividade). Portanto, a transitividade, de fato, não tem necessariamente a ver com verbos, pois uma ocorrência como "o filho de João" é considerada transitiva, embora não possua verbos.

Como vimos, em Prisciano, as formas declinadas do paradigma do pronome qui, quae, quod operam a distinção "reciprocidade vs. transitividade" nas construções de que fazem parte. Os gramáticos especulativos farão uso do paradigma pronominal em suas análises de relações de tipo "nome-verbo", "verbo-nome", "nome-nome", porém, de uma maneira diferente da que fizera Prisciano, pois, em sua análise semiformalizada, o paradigma pronominal abandona seu lugar de operador nas construções e transforma-se

\footnotetext{
${ }^{4}$ Hoc idem, id est qui, quotiens subiungitur nomini, quomodo hós apud Graecos, necesse est non solum ad nomen praepositum, sed etiam ad id subiunctum alterum uerbum proferri, ut uirum cano, qui uenit. Si nominatiuo nominatiuus adiungitur, ad eandem personam uerba referuntur: homo uenit, qui scripsit; sin duo obliqui sunt, ad aliam personam transitio fit uerborum uel in se reciprocatur, ut hominem, quem uitupero, accuso et memet, quem uitupero, accuso; sin alterum sit nominatiui, alterum uero obliqui, ad nominatiuum non fit transitio uerbi ab alia persona ad aliam, ad obliquum uero fit, ut homo uenit, quem accuso uel hominis misereor, qui uenit. Omnia tamen quae in transitione fiunt, possunt etiam in reciprocatione fieri.

Et quomodo qui et eius obliqui omnes ad nominatiuos omnium casualium bene referuntur, ut Vergilius qui scripsit; Vergilius cuius scripta extant; Vergilius cui gloria contingit; Vergilius quem laudant; Vergilius quo docente bene proficitur, sic et ex contrario nominatiuo eius omnes aliorum casus bene adiunguntur, ut qui scripsit bucolica Vergilius magnus poeta fuit; qui scripsit Aeneida Vergilii sunt georgica; qui scripsit Aeneida Vergilio gloria contingit; qui scripsit Aeneida Vergilium laudo; qui scripsisti Aeneida, Vergili, uiuis memoria; qui scripsit Aeneida Vergilio florent studia. Licet autem et praepostere haec dicere (PRISCIANO, 2, 127, 12-128, 7).
} 
em um conjunto de variáveis semiabstratas que expõem relações sintáticas de quaisquer tipos.

Apesar de seu grande débito com Prisciano em relação aos dados iniciais de sua pesquisa, os modistas afastaram-se dele em seu uso do paradigma pronominal qui, quae, quod. De fato, em sua teoria do caso, o modista Tomás de Erfurt (ca. 1310) não só se afasta das análises operacionais do pronome relativo, mas também passa a empregar outras noções: um cruzamento entre as categorias aristotélicas da substância (para as relações nominais) e da ação (para as relações entre nomes e verbos ou outras partes da frase) com noções da física do movimento.

\section{Tomás de Erfurt e a analogia do móvel}

O modismo ${ }^{5}$ foi um movimento de gramáticos que atuou principalmente em Paris e no Norte da Europa entre 1270 e 1330 (ROSIER, 1983; COVINGTON, 1984). Dá-se a eles a designação de modistas devido ao nome comum dos textos gramaticais que escreviam: "tratados sobre os modos de significar", esses tratados são também chamados de "gramáticas especulativas", em que a especificação, "especulativa", equivale a "teórica". São, assim, tratados de natureza teórica, sendo o latim ${ }^{6}$ a língua de análise. Modistas mais conhecidos foram Boécio da Dácia, Martinho da Dácia, Siger de Courtrai, Radulfo Brito e Tomás de Erfurt.

O Tratado sobre os modos de significar ou gramática especulativa, de Tomás de Erfurt, é o trabalho mais completo do movimento, não apenas por aparecer no final da terceira e última geração do modismo, mas também por possuir todas as partes que um tratado sobre os modos de significar poderia conter: uma discussão da metalinguagem, um estudo das partes da frase e uma descrição da sintaxe latina. Um tratado tão completo não era comum, porque os textos modistas normalmente só traziam uma discussão das partes da frase. A Grammatica speculativa teve uma notável fortuna: Peirce e Heidegger a estudaram; por muito tempo, foi atribuída ao franciscano João Duns Scotus (ca. 12661308), um dos pensadores escolásticos mais influentes da história intelectual do Ocidente.

Tomás de Erfurt costumava analisar sentenças de tipo "nome + verbo", como:

(1) Socrates currit.

[Sócrates NOM.MASC.S. corre.PRES.IND.3PS.]

Por meio de um procedimento que consistia em reduzi-las a sentenças de tipo "nome + est (cópula) + nome":

(2) Socrates est currens.

[Sócrates NOM.MASC.S. é.PRES.IND.3PS. corredor.NOM.MAS.S.]

Esse procedimento, chamado de redução à cópula, era a designação do verbo "ser" na terceira pessoa do singular latino: est. No séc. XIII, a cópula passou a ser entendida de acordo com uma analogia do movimento físico (motus) de um móvel que percorre a

\footnotetext{
${ }^{5}$ Os gramáticos especulativos do final da Idade Média (séc. XIII) são conhecidos como Modistae no mundo de expressão inglesa, em que se costuma manter a designação no latim original.

${ }^{6}$ A produção de Roger Bacon (ca. 1220-1292) incluiu também estudos gramaticais do hebraico, do árabe e do siríaco.
} 
distância entre duas substâncias no mundo (COVINGTON, 1984). De acordo com a Gramática especulativa, de Tomás de Erfurt, o movimento discursivo só é possível porque o verbo possui um modo de significar (se referir à) a separação entre coisas e estados de coisas, o que diferencia o verbo do nome. De fato, é esse modo de significar, que existe implicitamente no elemento "cópula" do verbo, que cria a distância ou separação (semântica) entre o nome e o verbo. Essa separação linguística é correlata à separação ontológica entre ens (o ser) e o esse (ser isto ou aquilo).

O modo da separação entre o nome e o verbo é chamado de modus distantis. Segundo Tomás de Erfurt, esse é o aspecto distintivo da essência de todo e qualquer verbo em relação a outras partes do discurso: Modus significandi generalissimus essentialis verbi est modus significandi rem per modum esse, et distantis a substantia - "O modo de significar essencial mais geral do verbo é o modo de significar a coisa por meio do modo do ser e (do modo) do distar da substância" (ERFURT, XXV, 44). Assim, o que garantiria que o significado da ação ou quaisquer movimentos denotados pelo sujeito (seu esse) se distinguisse do significado do próprio sujeito (seu ens) seria, basicamente, a existência de um "modo do distante" (modus distantis) ou "modo de distar da substância" no verbo, em virtude da cópula implícita.

Com base na analogia do movimento, a diferença básica entre verbos transitivos e intransitivos torna-se bastante simples: enquanto os verbos intransitivos, como "corre", "nasce" etc., significam um distanciar-se sine termino/sine significatione (sem objetivo definido/sem um "fim" explícito), os verbos transitivos, como "ler", "construir" etc., significam a mesma distantia (deslocamento do discurso), porém cum termino/cum significatione. Os verbos intransitivos significam uma distância que retorna ao princípio do discurso: descrevem, pois, um movimento autorreferencial (motus), circular. Assim, nas construções intransitivas "Sócrates corre" e "O pálido Sócrates", o limite da distância significada por um verbo, adjetivo ou particípio não vai além de uma autorreferência.

Como vimos, Tomás de Erfurt utilizou a analogia com o movimento físico para distinguir entre construções transitivas e intransitivas. Ele utiliza essa mesma distinção como uma noção geral para a sua teoria do caso, que, como veremos a seguir, é parte integrante do modelo dependencial que se encontra nos últimos capítulos de sua Gramática especulativa.

Erfurt apresenta sua teoria do caso da seguinte forma:

Em seguida damos uma descrição do caso. Em que se deve observar que, nas coisas separadas, encontram-se certas propriedades comuns, a saber: a propriedade do princípio e a propriedade do término. Igualmente, são encontradas certas propriedades gerais nas coisas, a saber: a propriedade "enquanto o 'que' é algo em si ou o 'que' o outro é", a propriedade "enquanto 'de quem' o outro é", a propriedade "enquanto 'para quem' e 'à qual' outra coisa é dada", e assim das outras propriedades semelhantes a essas, que são representadas pelas flexões do pronome quod ("que"): cuius ("de quem"), cui ("à qual"), etc. Embora o caso origine-se das primeiras propriedades, é da adição das segundas propriedades às primeiras que se originam as diferenças entre os casos. Portanto, o caso é o modo de significar acidental do nome mediante o qual o nome cossignifica a propriedade do princípio ou a propriedade do término e, de acordo com a diferença entre essas propriedades e as outras propriedades adicionais, o caso é dividido 
em seis espécies, a saber, em nominativo, genitivo, dativo, acusativo, vocativo e ablativo. $^{7}$

No excerto acima, o gramático franciscano propõe a distinção "princípio-término" para uma primeira diferenciação entre os casos do latim. Em posse dessa oposição, ele explica cada caso de acordo com a sua referência (posicional) à distinção "princípiotérmino" de duas maneiras diferentes: 1) enquanto o nominal funciona somente como princípio ou somente como término de uma ação, 2) enquanto o nominal pode funcionar tanto como princípio quanto como término de uma ação ou substância (ERFURT, XIX, 32-3). Portanto, ele faz um cruzamento de um critério posicional com um semântico, e o critério semântico origina-se da oposição entre os significados das categorias aristotélicas da ação e da substância. No mesmo excerto, Tomás de Erfurt especifica as outras seis propriedades semânticas de que se originam os sentidos particulares que explicam a diferenciação do sistema em seis casos. Por fim, ele formaliza esses cruzamentos e diferenciações com o emprego de cinco elementos do paradigma do pronome relativo quod ("que"): cuius ("de que"), cui ("a/para que") etc., e é só nesse momento que o paradigma de quod é incluído no sistema. O esquema abaixo explicita o resultado desses cruzamentos e sua formalização.

\section{$1 \quad$ Princípio (construções intransitivas)}

1.1 Princípio de uma ação somente: Nominativo (quod)

(3) Socrates $\rightarrow$ currit.

Sócrates.NOM.MASC.S. corre.PRES.IND.AT.3PS.

1.2 Princípio de uma ação: Genitivo (cuius)

(4) Socratis $\rightarrow$ interest.

A Sócrates.GEN.MASC.S. interessa.PRES.IND.AT.3PS.

2 Término (construções transitivas)

2.1 Término de uma ação ou substância indiferentemente: Genitivo (cuius)

2.1.1 Término de uma ação:

(5) $\quad$ Misereor $\rightarrow$ Socratis.

Tenho pena PRES. IND 1PS. de Sócrates.GEN.MASC.S.

\footnotetext{
${ }^{7}$ Consequenter de casu dicamus. Iuxta quod notandum, quod in rebus inveniuntur quaedam proprietates communes, scilicet proprietas principii, et proprietas termini. Item, inveniuntur quaedam proprietates generales in rebus, scilicet proprietas, ut quod est aliquid in se, vel quod est alterum; et proprietas cuius est aliud; et proprietas, ut cui est, et cui aliquid datur; et sic de consimilibus, quae repraesentatur per inflexionem huius nominis quod, cuius, et cui, etc., et a primis proprietatibus oritur casus, qui est modus significandi nominis. Sed a secundis proprietatibus superadditis primis oriuntur differentiae casus, vel casuum. Casus igitur est modus significandi accidentalis nominis, mediante quo, nomen proprietatem principii, vel termini consignificat. Et secundum harum proprietatum diversitatem, cum aliis proprietatibus superadditis, casus in sex species partitur, scilicet nominativum, genitivum, dativum, accusativum, vocativum, et ablativum (ERFURT, XIX, 32).
} 
2.1.2 Término de uma substância:

(6) Filius $\rightarrow$ Socratis.

o filho.NOM.MASC.S. de Sócrates.GEN.MASC.S.

2.2 Término de uma ação ou substância indiferentemente: Dativo (cui)

2.2.1 Término de uma ação:

(7) Faveo $\rightarrow$ Socrati.

Sou favorável.PRES.IND.AT.1PS. a Sócrates.DAT.MASC.S

2.2.2 Término de uma substância:

(8) $\quad$ Similis $\rightarrow$ Socrati

Semelhante.ADJ. a Sócrates.DAT.MASC.S.

2.3 Término de uma ação ou substância indiferentemente: Ablativo (a quo)

2.3.1 Término de uma ação:

(9) Utor $\rightarrow$ tog $\bar{a}$

Faço uso.PRES.IND.DEP.1PS. de uma toga.ABL.FEM.S.

2.3.2 Término de uma substância:

(10) Celer $\rightarrow$ pedibus.

Rápido.ADJ. com os pés.ABL.MASC.PL.

3 Término ou Princípio de uma ação somente - construções transitivas ou intransitivas

3.1 Término de uma ação: Acusativo (quem)

(11) Percutio $\rightarrow$ Socratem

Bato.PRES.IND.AT.1PS. em Sócrates.AC.MASC.S

3.2 Princípio de uma ação:

(12) Video Socratem $\rightarrow$ currere.

Vejo.PRES.IND.AT.1PS. Sócrates.AC.MASC.S. correr. PRES.INF.AT.

4 Término de uma ação estimulante apenas: Vocativo - construções transitivas

(13) $\quad O \rightarrow$ Thomas.

Ó.INTERJ Tomás!.VOC.MASC.S

Fonte: Desenvolvido a partir de Covington (1984, p. 78) 
A teoria do caso da Gramática especulativa é construída nocionalmente: a noção de uma distinção posicional baseada na analogia física "princípio-término" é cruzada com os significados mais gerais das categorias da ação e da substância da metafísica. Esses cruzamentos, adicionados às seis diferenças específicas de cada caso, dão origem aos significados das seis propriedades casuais, cinco dos quais são representados pelo paradigma de quod.

Como se vê, há um claro desenvolvimento a partir das ideias de Prisciano: o paradigma de quod deixa de ser um elemento formal que opera mudanças de sentido nas construções para se tornar um conjunto de variáveis para a formalização das relações geradas por um sistema de casos nominais. Vejamos agora se no séc. XVIII podem ser verificadas continuidades ou desenvolvimentos semelhantes.

\section{A descrição do caso nominal n'As duas línguas de Jeronymo Soares Barbosa}

As duas línguas, uma gramática bilíngue e com intenção pedagógica, foi publicada em Coimbra em 1807. O autor é muito claro ao definir sua concepção racionalista e universalista da linguagem:

A Gramática é uma ciência universal, como é a Lógica. Os princípios gerais de todas as línguas são os mesmos, como o são os do raciocínio e discurso [...] Toda diferença (entre as línguas) está nas formas acidentais externas [...] Qual será mais próprio e útil, aprender as regras da linguagem em geral no próprio idioma, ou no alheio? (BARBOSA, 1807, p. vi).

Com base no universalismo linguístico e em sua preocupação com o ensino, principalmente o das línguas clássicas, Soares Barbosa propõe o ensino e aprendizagem das formas acidentais (acidentes) para que os aprendizes cheguem com mais facilidade à substância, que é uma gramática constituída de regras ou princípios universais, iguais para todas as línguas. A consciência dessas regras facilitaria a aprendizagem de qualquer idioma. Onde o aluno encontraria mais prontamente essas regras? Em sua própria língua, no caso, a portuguesa. É por isso que n'As duas línguas, Soares Barbosa propõe o estudo do latim de forma contrastiva com a gramática do português.

No capítulo intitulado "Do caso", o gramático luso apresenta o sistema do caso nominal a partir da noção de diferentes tipos de relação entre os nomes:

Os nomes, assim portugueses como latinos, na sua primeira forma, tanto do singular, como do plural, não fazem parte da oração: porque exprimem os objetos em si mesmos sem relação alguma a outros. A palavra Homem, Homens (Homo, Homines) nomeia só esta espécie de indivíduos sem respeito algum a outra coisa. Mas estes objetos podem dizer relação a outros, e certo a dizem, quando se ajuntam em oração. (BARBOSA, 1807, p. 8).

Jeronymo declara que essas relações podem ser infinitas, mas que há algumas que são mais comuns, e que estas se distinguem por determinadas partículas: 
Mas as mais ordinárias e importantes são as que se escolherão para por meio de certas partículas ser juntas aos nomes. Tais são:

$1^{\mathrm{a}}$ a Relação Subjetiva, que faz da ideia exprimida pelo nome o Sujeito que fala, ou de quem se fala na oração;

$2^{\mathrm{a}}$ a Relação Vocativa, que faz da mesma ideia o Sujeito, com quem se fala na oração;

$3^{\mathrm{a}}$ a Relação Restritiva, que faz com que um nome, junto a outro, lhe restrinja a sua significação geral;

$4^{\mathrm{a}}$ a Relação Terminativa, que faz com um nome, ou sua ideia seja o Termo de outra relação;

$5^{\mathrm{a}}$ a Relação Objetiva, que faz com que a ideia, exprimida pelo nome, seja o Objeto de uma ação;

$6^{\mathrm{a}}$ a Relação Circunstancial, que faz dos nomes, ou de suas ideias, várias circunstâncias, que modificam ou explicam os termos das Proposições (BARBOSA, 1807, p. 8-9, grifo nosso).

No estado atual de nossas pesquisas a respeito do pensamento linguístico de Soares Barbosa, em comparação ou contraste com as ideias de Prisciano e de Tomás de Erfurt, ainda não temos condições de fazer uma análise mais aprofundada das diferenças ou permanências existentes n'As duas línguas em relação à tradição gramatical anterior - no caso específico deste artigo, e a linguistas da Idade Média e Antiguidade Tardia. Entretanto, no esquema apresentado por Jeronymo para o sistema de casos nominais, podemos observar uma noção inusitada na explicação semântica dos seis casos clássicos da GT: são as relações distintas, e não as desinências, que explicam as diferenças entre os casos: relação subjetiva, relação vocativa etc. Também se nota que o gramático português faz uso de formalizações do tipo "preposições + pronome interrogativo" para representar as relações nome-verbo e vocativo-nome $\left(1^{\mathrm{a}}\right.$ e $\left.2^{\mathrm{a}}\right)$. Já as designações "restringir" e "Termo", utilizadas por ele, sustentam a permanência de noções modistas (como "princípio-término" e nomenclaturas utilizadas nas seções em que Tomás de Erfurt discute os verbos na Gramática especulativa). Portanto, do ponto de vista de uma primeira abordagem, há diferenças marcantes, bem como indícios de permanência de ideias, na vertente filosófica da GT que vai de Varrão a Soares Barbosa.

\section{Considerações finais}

De acordo com o que foi discutido neste artigo, é possível concluir que há um claro desenvolvimento de teorias gramaticais da Antiguidade Tardia no final da Idade Média. Como se viu, Prisciano recolheu materiais gregos e romanos e desenvolveu uma análise morfossintática uniforme e filosoficamente informada. No Medievo, o trabalho de Prisciano é desenvolvido por Tomás de Erfurt, que explora novos horizontes, fazendo uma síntese entre Aristóteles e Prisciano, criando, no processo, uma teoria do caso nominal altamente sofisticada.

A compreensão dos desenvolvimentos que vão de Tomás de Erfurt a Jeronymo Soares Barbosa, do ponto de vista da pesquisa feita pelo autor deste artigo até o momento, torna-se mais problemática quando se tenta entender as permanências e rupturas entre 
Tomás e o que veio depois dele, na tradição que convencionamos chamar de gramática filosófica, porque Soares Barbosa parece afastar-se muito do tipo de trabalho feito por Tomás de Erfurt e Prisciano, embora o gramático português sustente pressupostos básicos que são semelhantes aos do modista e do gramático de Constantinopla, por exemplo: a assunção de uma gramática universal ou de uma razão $(\log o s)$ subjacente a todas as línguas. Certamente, futuros estudos dos marcos do pensamento sobre as línguas e a linguagem que antecederam Soares Barbosa e vieram depois dos modistas - por exemplo, Sanctius (final séc. XVI) e os gramáticos de Port-Royal - farão grande diferença na direção de um esclarecimento dessas dificuldades. Todavia, no momento, a distância entre Prisciano e Soares Barbosa parece sugerir nada menos do que uma quebra paradigmática de proporções copernicanas. O que se evidencia principalmente com respeito à forma de análise dos fenômenos, que parece ser muito mais minuciosa e epistemologicamente embasada nos antigos e, principalmente, nos medievais do que no racionalista português.

Entretanto, apesar dessas dificuldades, e das especificidades ou ideias originais que diferenciam os antigos e os medievais de Jeronymo Soares Barbosa, algumas das noções herdadas da Antiguidade e Idade Média têm, como foi visto neste artigo, uma visível continuidade na teoria do caso nominal que chega ao início do séc. XIX, e estão coligidas n'As duas línguas. Dadas essas evidências iniciais, como hipótese de trabalho, sugerimos que a sobrevivência dessas noções ou procedimentos (como a noção de gramática universal, de princípio-término e o uso do paradigma pronominal) na teoria do caso nominal latino da GT, da Antiguidade Tardia ao final do séc. XVIII e início do séc. XIX, explica-se pelos fundamentos epistemológicos comuns de um eixo lógicometafísico e, sobretudo, aristotélico da GT, que convencionamos chamar de gramática filosófica.

\section{REFERENNCIAS}

ARISTÓTELES. Metafísica. In: YEBRA, V. G. (Ed.). Metafísica de Aristóteles. Madrid: Gredos, 1970.

Órganon: Categorias, Da interpretação, Analíticos anteriores, Analíticos posteriores, Tópicos, Refutações sofísticas. Tradução de Edson Bini. 2. ed. São Paulo: Edipro, 2010.

BARBOSA, J. S. As duas línguas, ou grammatica philosophica da lingua portugueza comparada com a latina, para ambas se aprenderem ao mesmo tempo. Coimbra: Real Impressão da Universidade, 1807.

BORGES NETO, J.; DASCAL, M. De que trata a lingüística afinal? In: BORGES NETO, J. Ensaios de filosofia da lingüística. São Paulo: Parábola, 2004. p. 31-65.

BRUN, J. O estoicismo. Lisboa: Edições 70, 1986.

COVINGTON, M. A. Syntactic theory in the high middle ages. Cambridge: Cambridge University Press, 1984.

KELLY, L. G. The mirror of grammar: Theology, Philosophy and the modistae. Amsterdam/Philadelphia: John Benjamins Publishing Company, 2002. 
KOERNER, E. F. K. Models in linguistic historiography. In: KOERNER, E. F. K. (Org.). Practicing linguistic historiography: selected essays. Amsterdam/Philadelphia: John Benjamins Publishing Company, 1989. p. 47-59.

PRISCIANO. Institutiones grammaticae. In: KEIL, H.; HERTZ, M. (Ed.). Grammatici Latini: Prisciani institutionum grammaticarum libri i-xviii. Leipzig: Teubner, 1855.

ROBINS, R. H. Pequena história da linguística. Rio de Janeiro: Ao Livro Técnico, 1987.

ROSIER, I. La grammaire spéculative des modistes. Lille: Presses Universitaires, 1983.

SWIGGERS, P. Modelos, métodos y problemas en la historiografía de la lingüística. In: NUEVAS APORTACIONES A LA HISTORIOGRAFÍA LINGÜÍSTICA, 4: 2003, La Laguna. Actas... La Laguna: ARCO/LIBROS, S. L., 2004. p. 113-45.

TOMÁS DE ERFURT. Tratado sobre os modos de significar ou gramática especulativa. In: BECCARI, A. J. Uma tradução da grammatica speculativa, de Tomás de Erfurt, para o português: acompanhada de um estudo introdutório, notas e glossário. $2013.500 \mathrm{f}$. Tese (Doutorado em Letras) - Setor de Ciências Humanas, Letras e Artes, Universidade Federal do Paraná, Curitiba, 2013.

TRASK, R. L. Dicionário de linguagem e linguística. São Paulo: Contexto, 2011.

VALENZA, G. M. De lingua latina, de Marco Terêncio Varrão: tradução dos livros viii, ix e x. 2010. 174 f. Dissertação (Mestrado em Letras) - Setor de Ciências Humanas, Letras e Artes, Universidade Federal do Paraná, Curitiba, 2010.

VARRÃO, M. T. Livros viii a x. In: VALENZA, G. M. De lingua latina, de Marco Terêncio Varrão: tradução dos livros viii, ix e x. 2010. 174 f. Dissertação (Mestrado em Letras) - Setor de Ciências Humanas, Letras e Artes, Universidade Federal do Paraná, Curitiba, 2010.

Recebido em: 03/09/2017

Aprovado em: 06/11/2017 